\title{
THE COMPLEXITY OF THE IMPLICATIONS OF GLOBALIZATION IN THE CONTEXT OF THE CURRENT GLOBAL ECONOMY
}

\author{
Raluca Ionela CREȚOIU, Ph.D. candidate \\ Free International University of Moldova
}

\begin{abstract}
Globalization represents a controversial phenomenon both because of its complexity and because of the various implications it has on the global economy. Globalization will act simultaneously on many levels, its effects being correlated with the diversity of the angles from which this phenomenon can be approached from - economic, social, politic, cultural, philosophic etc.

The article represents an incursion into the issue regarding the implications and effects of globalization grouped in several areas of analysis such as the disappearance of borders, the effects on culture, the effects on the education, the impact on labour market impact and the phenomenon of immigration, the effects of globalization in the context of the food crisis underdevelopment and poverty.

To complete the analysis that points out enough elements considered to be negative, at the end of the article, there are also approached the development opportunities that globalization can offer in terms of boosting the economic exchanges, the exchange of genuine cultural values and ensuring a transfer of information at a global scale, so necessary for the scientific and technological progress.

The conclusions of the article weighs the many aspects highlighted, both negative and positive, and suggests a series of useful research directions in order to fathom the complex features of this concept so controversial globalization.
\end{abstract}

Keywords: globalization, labour force migration, underdevelopment, global problems

JEL Classification: $\mathrm{F}_{15}, \mathrm{~F}_{4}, \mathrm{~F}_{6}$

\section{Literature review}

The issue of globalization and its influences has been approached by numerous specialists, a lot of views and standpoints standing out. Globalization is seen either as a artificial phenomenon, imposed by the neoliberal current, or as a phenomenon resulting from the unprecedented development of communications technologies and more and more complex commercial trades from the second half of the twentieth century.

Experts distinguish two major dimensions of the phenomenon of globalization in the context of its evolution: (Gunter G. Bernhard, Van der Hoeven Rolph, 2004, p. 7-43) on the one hand, globalization seen as a manifestation of a 
combination of factors including: trade, investment, technology, transborders production systems, flows of information and global communications and respectively the process of increasing homogenization of policies and institutions around the world, such as liberalization of capital markets and trade, international agreements on intellectual property, standardization of policies and practices specific to the international law etc. In this context, globalization can be seen also as a multidimensional process of creating some international networks. (Brady David, Beckfield Jason, Zhao Wei, 2007, p. 313-334) The nodes are represented by individuals, organizations and national states, while relationships are developed under the notions of trade, investments, consumption and migrations. Conceptualizing globalization as a multidimensional training of networks helps identify different levels of analysing the process of globalization. Globalization will involve local, regional, national and international level of social life. Thus, globalization becomes easier to see in terms of flows of people, capital, information, goods and services. (Alderson S. Arthur, 2004, p. 81-122)

However, on the background of globalization, we have seen an increase in opportunities and actions related to closing strategic alliances, many companies promoting a business strategy that involves cooperation in one form or another (mixed companies, licensing, co-production agreements, joint research programs, etc.). (Ungureanu Gabriela, 2010, p. 71-72)

The effects of globalization are complex and inter-related. Thus, the studies show that the phenomenon of globalization can have implicit effects on social and fiscal policies - on most striking manifestation of the phenomenon of globalization, the effective tax on capital increasing for most OECD countries. (Dreher Axel, 2003, p. 4-6)

In terms of the welfare of a state (accumulation of income and reserves the state makes at a certain moment), globalization has not had relevant effects, although some experts have argued otherwise until recently. It is possible that the constitutional structure and the size of the elderly population actually have the greatest influence on the variation of a state's welfare. (Brady David, Beckfield Jason, Seeleib-Kaiser Martin, 2005, p. 921-925)

From the point of view of the social acceptance of globalization, we can notice a number of social phenomena that affect the identity of each individual. Thus, the experts believe that, currently, most people develop a dual cultural identity that combines their local cultural identity with the identity of a ,global" culture. (Arnett Jeffrey Jensen, 2002, p. 774-783) Also, each person is caught in the vortex of the consumer culture, exacerbated by the globalization phenomenon by opening new channels of trade and the unprecedented evolution of the Internet. (Bauman Zygmunt, 1999, p. 81)

At the same time, modern consumers, implicitly in the context of globalization, have become more demanding, less tolerant of the quality of products or services and less sensitive to price in relation to favourite brands. (Gârdan Daniel Adrian, Geangu Iuliana Petronela, 2009, p. 1-6) The possibilities that consumers have currently have determined as well a critical attitude towards manufacturing companies which do not have an ethical behaviour, an 
overwhelming proportion of the consumers refusing to consume the products of these companies. (Geangu, Iuliana Petronela, Ionel Dumitru, Daniel Adrian Gârdan, 2013, p. 182-194)

\section{Main categories of globalization's implications at the present time}

Currently, the complex dynamics of human civilization requires a series of major changes to both social and economic, political and even biological levels. Humanity is currently engaged in a variety of exchanges and networks, which often have resulted in the emergence, and development of some imbalances. These imbalances manifest as global issues.

The problems facing mankind such as underdevelopment and lack of food, the rapidly rising of population, the shortage of raw materials and energy, the expanding of urbanization, the massive spendings needed for scientific research in order to better understand the cosmos and the technological progress and, implicitly, the increase of living standard and well-being, the militarization and the overgrowth in military spendings, the increase of environmental pollution and many others have become global issues with major implications for the entire world on multiple levels: social, economic, political, environmental, etc.

The phenomenon of globalization requires a complex understanding of the factors responsible at national and international level, the development of an ample vision in order to offer the opportunity to successfully manage all challenges. In order to substantiate and implement the viable strategies to manage crisis situations and challenges mentioned above, the global issues should be studied in a broader time horizon, on several levels simultaneously. Creative and efficient use of production factors, identifying ways of developing these, not encroaching on the environment, is an essential prerequisite for the real progress of humanity. Sustainable development cannot take place without a set of interrelated measures aimed at the very global nature of the current challenges and the very close relationship between production, management and proper use of natural resources.

The implications that globalization will presently have can be grouped in the following main possible directions:

a. The implications of globalization from the point of view of the disappearance of borders

One of the most important features of the globalization process refers to the concept of border change itself. Globalization has determined the alteration until extinction of the concept of the border, not only in terms of national identities of some geographical territories but especially in terms of various aspects of human activity, such as the transfer of knowledge, capital, the culture or politic activity. The concept of frontier in the classical sense was used in the sense of delimitation, of establishing separation between different entities. In the present context of globalization event, this led to the reinterpretation of the concept, borders become more ,vague” and „unsafe”. In fact, globalization has led to a sharp growth of these borders, their permanent "reinvention”, an adaptation to the needs related to 
exchanges and global processes. Thus, an accentuated mobility of the production factors was impelled - labour, capital, know-how etc. Also, the mobility of goods and services related to production processes, the consumption mobility has increased.

However, currently, there are different degrees of mobility and global integration of production factors, a thing which leads to imbalances and disparities. Thus, the capital markets are strongly globally integrated, while labour markets are at the opposite end. The lack of synchronization between the different markets associated with the production factors is one of the main sources of the current imbalances, having long-term implications.

\section{b. The implications of globalization on culture}

Another category of effects of globalization refers to the effects that globalization has had on national cultures. Here, the analysis reveals multiple changes and controversies. To what extent the dissolution of borders (implicitly of those of cultural nature) is a negative or positive phenomenon for the development of human civilization. Certainly, the increase of the dynamics of the forms of cultural expression, the possibility of rapid communication from one language to another, the possibility that different categories of consumers of culture to have better access to the desired cultural services and goods, the possibility of interference and sharing of superior cultural values regardless of the physical distances - all of these - undoubtedly represent positive elements that can contribute to the spiritual development of the humanity, to the creation of the common cultural dowry of humanity. On the other hand, the cultural dominance of certain states, the imposition of some values over other national values, the often unfortunate connections between the economic and political power of some states and the imposition of these values are elements that raised and still raise serious questions in terms of the real development of civilization.

\section{c. The implications of globalization on education}

Globalization could not affect to a large extent the educational process because it is closely related to the exchange of culture, to the learning processes and the knowledge transfer from all fields of human activity. Analysing the influences of globalization at the education level there are highlighted a number of issues related both to the process of supply, delivery and consumption of educational services and to the image and attitude of individuals in relation to education itself. The profound transformations in the information technology, telecommunications and the Internet have determined irreversible mutations in education also. The possibility of cultural and information exchanges on a global scale has created a global market of educational services, causing major changes in the way they are consumed and designed. Educational institutions have access to global clients, organizations transfer know-how through some learning systems accessible to everyone, going over old cultural, language etc. barriers. However, the imposition of English language as a universal language of learning contents available online has created ample opportunities for the educational institutions from the British cultural space to impose its own cultural model and the values of 44 
its educational system. Beyond the positive effects in terms of boosting the adventure of human knowledge, globalization also causes negative effects on educational systems that do not have regulatory and auto-retrenchment mechanisms of some inappropriate educational approaches. The adoption of some universal formulas, of some ,global” teaching, grading, evaluating systems must be made with maximum discretion, taking into account the specific of the psychology and local culture, of the different training needs a national economy has at any given time.

\section{d. The implications of globalization on the labour market}

The labour market at the level of the world economy has undergone profound changes over the past 50 years. The causes of these changes are not to be found only in the unprecedented evolution of technology, but also in political, economic regime, trade policy and even consume changes the world knew in the time mentioned. Boosting the transport of goods and persons, eliminating taxes and barriers for labour migration has determined the emphasis of flows of individuals looking for a job and has led, in time, to the manifestation of some particular trends for different regions. Thus, national economic systems or particular ways of development of the work demand-supply ratio have manifested one at a time, that had different approaches to the work processes - „Asian tigers”, „low-wage countries", brains exporting countries, etc. The labour migration flows are influenced by employment potential existing in each national economy, by the economic, fiscal and social policies promoted by each state. Specialists bring various arguments for boosting the trade exchanges between the different types of economies - developed, industrialized, developing, etc. The conclusion is that, on the labour market as well, like on other markets, globalization has encouraged some states and disfavoured others, the effects manifesting asynchronously.

\section{e. The implications of globalization on the level of immigration}

The migration phenomenon has known along history many developments and particularities. Globalization has enhanced some of them and inhibited others. North-south and east-west classical migration trends continued, but sensitively modified by the new cultural and economic relations that have settled between these areas along with the manifestation of globalization. One of the key motivations of the migration process referred especially to the labour force migration. Social and even economic relations between the populations that have migrated and the country of origin have determined new evolutions in the context of globalization. Technology has allowed exchanges between immigrant communities and the native economy to be held more easily and quickly, a thing which led in time to the development of certain exchange relations between economies (the origin one and that in which the migrants naturalized in). Although consumption globalized as well, the gaps between the demand and supply of local labour force have led to numerous disparities resulting from the labour force migration in certain areas. This led to protectionist policies (as it is, for example, the policy adopted by England until recently), and the erection of some barriers in the way of migration. In the long term, despite the trends of regionalization and streamlining the trades (including the flow of people) - see the example of the 
European Union, it is difficult to predict whether policymakers will identify effective measures to balance the demand and supply of labour.

\section{f. The implications of globalization in terms of poverty}

The phenomenon associated to poverty is a scourge for the world economy. A number of countries and areas of the world are excessively disadvantaged in terms of resources to ensure the existence and development of a viable economic system. This inevitably leads to extreme living conditions for the vast mass of the population and the manifestation of the phenomenon of poverty. Globalization has had contradictory effects in this regard.

Thus, although the boosting of foreign trade, of the access to resources and raw materials, to capital and labour force (elements associated with the general effects of globalization considered to be positive for any national economy) should have generated positive effects as well for some states lacking some resources, this did not happen in all cases. Moreover, on the background of globalization, we are witnessing actually to the widening of the gaps between very rich states and those very poor. This widening of the gaps leads to the manifestation of a true vicious circle, the poor countries become poorer the smaller their chances to integrate into the world economic and participate in the international division of labour force and exchanges that would bring them the resources they need.

\section{g. The implications of globalization in terms of food crisis and} underdevelopment

The issue of food crisis and underdevelopment is organically linked to that of poverty. The food crisis occurred on the ground of the explosive growth of the world population and of the overall demand exceeding the agricultural production capacity. Significant effects of further propagation of the food crisis are determined by global environmental problems - uncontrolled pollution, deforestation, the loss of some arable lands due to their irrational use for industrial constructions, the lessening of the freshwater available etc. In addition to the production capacities for some states already known on the world agricultural market, globalization should allow politic and social decision factors the unfolding of more joint programs that will ultimately aim the supply migration in case of overproduction from developed countries towards underdeveloped countries, even in terms of their inability to pay. The development of some initiatives to highlight the human potential of underdeveloped states, the implementation of performant agricultural technologies at the level of their economies, the humanitarian programs and other solutions of this kind may represent elements that counteract the de facto widening of the economic gaps mentioned above.

\section{Development opportunities offered by globalization}

The phenomenon of globalization has been assessed so far both in terms of its adverse effects for some national economies or socioeconomic categories and in terms of the positive effects that have accompanied its development and affirmation. 
Thus, economically, there are real development opportunities once the states create their viable mechanisms to control their participation in world trade. Applying some intelligent export strategy, implementing a set of measures to overcome the simple reducing of customs duties may represent elements that enhance the welfare of national economies seeking active engagement in the current world trade mechanism. This openness to the global market should however be managed very firmly, with the help of some institutions and mechanisms proper to the concerned state to gradually addresse the integration process. Without a coherent strategy in this respect, some states have already suffered, as a result of the contact with the globalization of trade, the erosion of their domestic production capacity, of the mechanisms of internal goods consumption, outdated qualitatively by the influx of imported products.

Also economically, globalization offers development opportunities for the developing countries by means of the activities developed by the transnational companies as well. They offer higher wages rewards on the local market, they bring technology and know-how to the economy, contributing at the same time to the transfer of certain managerial cultures etc.

Another source of opportunities is represented by connecting the world states to the global computer networks. The investments into the IT infrastructure, into the specialized personnel offer the possibility of connection to a true highway of information. The benefits are huge in terms of cooperation and integration in the network of technical and technological values from the global level, the real-time and low-cost access to information from various fields of economic development boosting the development of the economic agents and the capacity of the respective state to impose its own technologic values on the world market.

Culturally, globalization can bring opportunities, although, from this point of view, there were discussed the hazards or negative effects visible in some cases. However, the cultural openness offered by globalization can be used advantageously and creatively in the conditions of the existence of a certain intellectual maturity and a greater institutional competence of the states in question. The access to real culture, to the creative values of all peoples of the world presupposes enriching the cultural universe of every citizen, the possibility of developing joint cultural projects, a transfer of ideas and the identification of some new forms of expression of the cultural creativity.

\section{Conclusions and proposals}

Despite the many controversies, the trends for and against globalization, this complex phenomenon must be examined with the utmost objectivity as it is part of the socio-economic reality of the beginning of the century and, as such, cannot be and should not be ignored.

The implications that globalization has on multiple levels determine the need for a deep and lasting analysis, aimed to clarify not only the content of these implications, but also show the future trends and correlations that exist between them.

Analysing the substrate of some phenomena that occur in the context of globalization, we can extract some conclusions that we consider most important overall:

- The widespread corruption of the institutions, the lack of institutions or their completely inadequate organization, the lack of vision and the foundation of some inappropriate economic policies are the main causes of the failure of some national economies in the effort to integrate into the global economic cycle. 
- The politics of force, the unjustified imposition of a set of macroeconomic neoliberal nature measures to all states are the main causes of the failures registered in the activity of some institutions such as the IMF or World Bank, considered to be ,agents of globalization”.

- Job insecurity, forced relocation of some employees within transnational companies, income disparities between the various categories of employment maintain and contribute to the destabilization of the different national, cultural, etc. communities, affecting their value system and security.

- The openness to the global economy or to the free trade does not ensure in any circumstance the economic development of states, this openness is necessary to be made gradually and individually as each economy has its peculiarities and its own production mechanisms to be protected and helped integrate into the global market.

- The global issue of the environment can be managed only by implementing some regulations that take into account the extent of the phenomenon and to be applied and applicable not only nationally but internationally as well in a long-term unified and coherent form.

\section{REFERENCES}

Alderson S. Arthur (2004), "Explaining the Upswing in Direct Investment: A Test of Mainstream and Heterodox Theories of Globalization", Social Forces, vol. 83, issue 1: 81-122.

Arnett Jeffrey Jensen (2002), "The Psychology of Globalization”, American Psychologist, vol. 57, no. 10: 774-783.

Brady David, Beckfield Jason, Seeleib-Kaiser Martin (2005), "Economic globalization and the welfare state in affluent democracies, 1975-2001", American Sociological Review, vol. 70, issue 6: 921-948.

Brady David, Beckfield Jason, Zhao Wei (2007), "The consequences of economic globalization for affluent democracies", Annual Review of Sociology, vol. 33: 313334.

Dreher Axel (2003), "The influence of globalization on taxes and social policy - an empirical analysis for OECD countries", Economics Department Discussion Papers Series, University of Exeter, School of Business and Economics, ISSN 1473-3307, http://business-school.exeter.ac.uk/documents/papers/economics/2003/0301.pdf

Gârdan Daniel Adrian, Geangu Iuliana Petronela (2009), "Ways to Increase Fidelity of Textile Products Consumers", Available at SSRN: http://papers.ssrn.com/sol3/papers.cfm?abstract_id=1436002.

Geangu Iuliana Petronela, Dumitru Ionel, Gârdan Daniel Adrian (2013), "Ethical and Legal Aspects of Marketing Activity in the Field of Dental Healthcare Services", Proceedings of the 3rd IISHSS- International Conference on Law and Social Order, April 25-26, New-York: Addleton Academic Publishers, 182-196.

Gunter G. Bernhard, Van der Hoeven Rolph (2004), "The social dimension of globalization: A review of the literature", International Labour Review, vol. 143, no. 1-2: 7-43.

Ungureanu Gabriela (2010), "From Cooperation to Globalization", Annals of Spiru Haret University, Economic Series, Volume 1(10), Issue 3: 71-78.

Zygmunt Bauman (1999), Globalizarea şi efectele ei sociale, Bucureşti, Antet. 